\title{
A proinflammatory peptide from Helicobacter pylori activates monocytes to induce lymphocyte dysfunction and apoptosis
}

\author{
Åsa Betten, ${ }^{1,2}$ Johan Bylund, ${ }^{2}$ Thierry Cristophe, ${ }^{3}$ François Boulay, ${ }^{3}$ Ana Romero, ${ }^{1}$ \\ Kristoffer Hellstrand, ${ }^{1}$ and Claes Dahlgren ${ }^{2}$ \\ ${ }^{1}$ Department of Virology, University of Göteborg, Göteborg, Sweden \\ ${ }^{2}$ Department of Medical Microbiology and Immunology, University of Göteborg, Göteborg, Sweden \\ ${ }^{3}$ Département de Biologie Moléculaire et Structurale, Commissariat à l'Energie Atomique, Grenoble, France \\ Address correspondence to: Kristoffer Hellstrand, Department of Virology, \\ University of Göteborg, Guldhedsgatan 10B, S-413 46 Göteborg, Sweden. \\ Phone: 46-31-3424731; Fax: 46-31-3424960; E-mail: kristoffer.hellstrand@microbio.gu.se.
}

Received for publication June 4, 2001, and accepted in revised form September 5, 2001.

Infection with Helicobacter pylori causes chronic gastritis, which is characterized by a dense mucosal infiltration by inflammatory cells such as monocytes/macrophages. $H$. pylori-induced inflammation is a risk factor for the development of gastric adenocarcinoma, but the mechanisms involved in $H$. pylori-associated carcinogenesis are poorly understood. A cecropin-like H. pylori peptide, $\mathrm{Hp}(2-20)$, was found to be a monocyte chemoattractant and activated the monocyte NADPH-oxidase to produce oxygen radicals. The receptors mediating monocyte activation were identified as FPRL1 and the monocyte-specific orphan receptor FPRL2. Hp(2-20)-activated monocytes inhibited lymphocytes with antitumor properties, such as $\mathrm{CD}^{2} 6^{+}$natural killer (NK) cells and $\mathrm{CD} 3 \varepsilon^{+} \mathrm{T}$ cells. The changes observed in NK cells and T cells - a reduced antitumor cytotoxicity, downregulation of CD3 $\zeta$ expression, and apoptosis - were mediated by $\mathrm{Hp}(2-20)$-induced oxygen radicals. Histamine, a gastric mucosal constituent, rescued NK cells and T cells from inhibition and apoptosis by suppressing $\mathrm{Hp}(2-20)$-induced oxygen radical formation. We conclude that $H$. pylori expression of this monocyteactivating peptide contributes to its ability to attract and activate monocytes and reduces the function and viability of antineoplastic lymphocytes. These novel mechanisms may be subject to local, histaminergic regulation in the gastric mucosa.

J. Clin. Invest. 108:1221-1228 (2001). DOI:10.1172/JCI200113430.

\section{Introduction}

Compelling epidemiological evidence links the chronic gastritis associated with infection with Helicobacter pylori to the development of gastric adenocarcinoma (1), the second leading cause of cancer-related death in the world (2). One of several mechanisms that have been proposed to account for the increased cancer risk is that gastric carcinoma occurs as the result of an inappropriately regulated local host immune response to the infection. A general feature of this response is a dense infiltration of the subepithelial gastric lamina propria by phagocytes, mainly monocyte/macrophages and neutrophilic granulocytes, and lymphocytes, including those of relevance to defense against arising and established gastric cancer such as natural killer (NK) cells and T cells (3-6).

To further understand the mechanisms underlying H. pylori-induced carcinogenesis, it is of interest to explore interactions between $H$. pylori and leukocytes infiltrating the infected tissue. $H$. pylori cause a chronic, often lifelong infection of the gastric epithelial cells, but the bacteria do not normally penetrate into the subepithelial lamina propria. Thus, modulation of leukocyte function is likely to depend on the release of soluble bacterial products (7-9). In this study, we have investigated the immunomodulatory properties of a cecropin-like $H$. pylori-derived peptide, $\operatorname{Hp}(2-20)(10,11)$. We show that $\operatorname{Hp}(2-20)$, acting via two receptors of the FPR family of chemoattractant receptors, attracts monocytes and activates monocytes to generate NADPH-oxidase-derived oxygen radicals. Monocytes activated by $\mathrm{Hp}(2-20)$ suppressed functions of NK cells and T cells and triggered apoptosis in both cell types; these inhibitory events were mediated by oxygen radicals. Histamine, a gastric mucosal constituent, protected NK cells/ T cells from monocyte-induced functional inhibition and apoptosis. We hypothesize that $\mathrm{Hp}(2-20)$ contributes to the accumulation and activation of monocytes in chronic gastritis, and that the $\mathrm{Hp}(2-20)-$ induced formation of mutagenic oxygen radicals with ensuing inhibition of antineoplastic lymphocytes may be of relevance to the increased cancer risk in H. pylori-infected gastric tissue.

\section{Methods}

Peptides and chemicals. The peptides used, $\mathrm{Hp}(2-20)$, AKKVFKRLEKLFSKIQNDK, and WKYMVm, were synthesized and handled as described (11). Histamine dihy- 
drochloride was from Maxim Pharmaceuticals (San Diego, California, USA), ranitidine hydrochloride from Glaxo (Mölndal, Sweden), and human recombinant IL-2 from Genzyme (Stockholm, Sweden).

Separation of lenkocytes. Peripheral blood was obtained from blood donors at Sahlgren's Hospital, Göteborg, Sweden. After Ficoll-Hypaque centrifugation (12), mononuclear cells were separated into lymphocytes and monocytes using the countercurrent centrifugal elutriation (CCE) technique, as described in detail elsewhere (12). This procedure yielded one
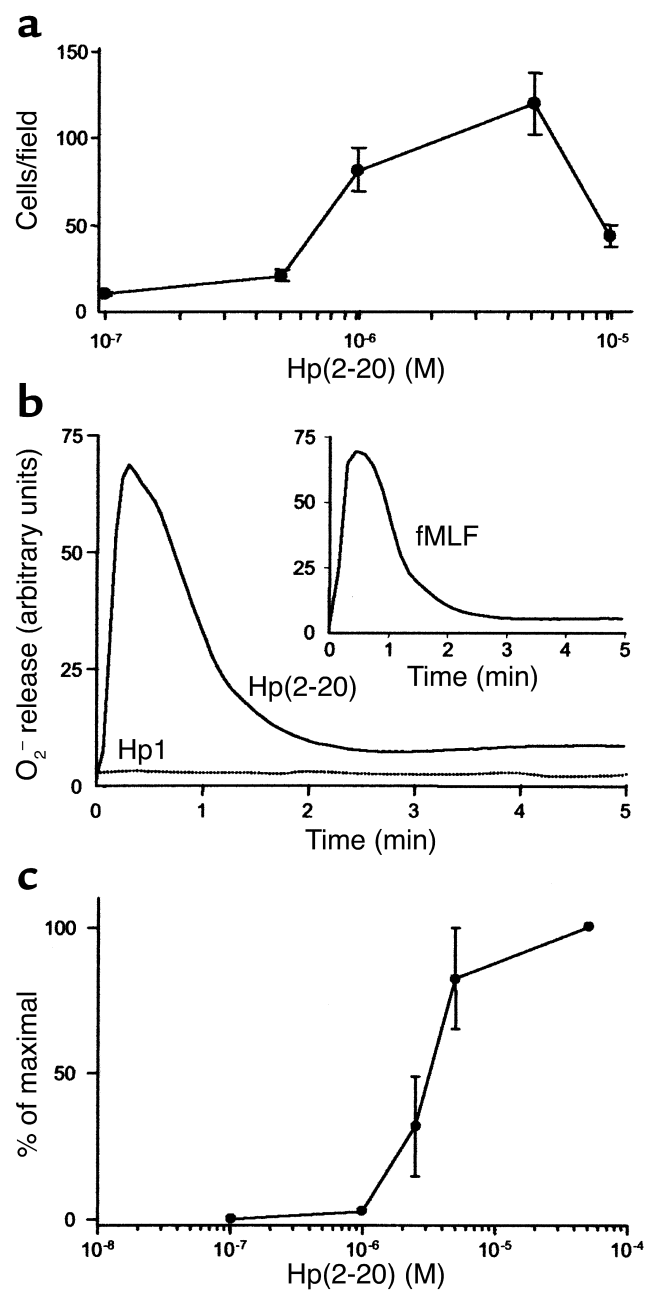

\section{Figure 1}

$\mathrm{Hp}(2-20)$-induced monocyte chemotaxis and activation of the monocyte NADPH-oxidase. Monocyte transmigration after $90 \mathrm{~min}-$ utes in response to different $\mathrm{Hp}(2-20)$ concentrations was determined using a ChemoTx multiwell chamber system. Migration was determined microscopically by counting cells in the lower compartments. (a) $\mathrm{Hp}(2-20)$ induced chemotaxis in human monocytes in a dose-dependent manner. Mean values \pm SEM of three separate experiments. $\mathrm{Hp}(2-20)(50 \mu \mathrm{M})$, but not the control peptide Hp1 (50 $\mu \mathrm{M})$, triggered superoxide anion production in monocytes (b) with kinetics similar to that induced by the formylated peptide $\mathrm{FMLF}$ (inset). The $\mathrm{Hp}(2-20)$-induced superoxide anion release was dosedependent within the micromolar range $(\mathbf{c})$. One representative experiment out of five ( $b$ and inset), and mean values \pm SEM of five separate experiments $(\mathbf{c})$. fraction with $>90 \%$ monocytes (at a flow rate of $20-22$ $\mathrm{ml} / \mathrm{min}$ ) and two lymphocyte fractions, one enriched for $\mathrm{CD} 3 \varepsilon^{-} / 56^{+} \mathrm{NK}$ cells $(45-50 \%$, at $15-16 \mathrm{ml} / \mathrm{min})$ and one enriched for $\mathrm{CD} 3 \varepsilon^{+} / 56^{-} \mathrm{T}$ cells $(70-80 \%$, at $13-14 \mathrm{ml} / \mathrm{min}$ ).

Monocyte chemotaxis and NADPH-oxidase activity. Monocyte chemotaxis was determined using ChemoTx multiwell chambers (Neuro Probe Inc., Gaithersburg, Maryland, USA) according to instructions provided by the manufacturer. Monocytes were allowed to migrate through the filters, and accumulation of cells in the lower compartments was determined microscopically after a 90 -minute incubation at $37^{\circ} \mathrm{C}$. NADPH-oxidase activity was determined using an isoluminol-enhanced chemiluminescence (CL) system that quantitates extracellular reactive oxygen species (ROS) (13).

Assays of apoptosis. Apoptosis was monitored by use of flow cytometry, as described elsewhere (14). T cells or NK cells were gated after exposure to monocytes, and the gate was set to comprise lymphocytes with a reduced forward scatter and an increased right-angle scatter characteristic of apoptosis (12). Two additional methods were used to determine apoptosis in NK cells and T cells: analysis of DNA strand breaks by TUNEL assay and annexin $\mathrm{V}$ staining, as described elsewhere $(14,15)$.

Detection of lymphocyte surface and intracellular antigens. One million cells were stained with appropriate FITCand phycoerythrin-conjugated (PE-conjugated) $\mathrm{mAb}$ 's (Becton Dickinson, Stockholm, Sweden; $10 \mu \mathrm{l} / 10^{6}$ cells), as described elsewhere (15). Cells were analyzed by use of flow cytometry on a FACSort with a Lysys II software program (Becton Dickinson). Lymphocytes were gated on the basis of forward and right-angle scatter. The flow rate was adjusted to less than 200 cells $\times \mathrm{s}^{-1}$, and at least $5 \times 10^{3}$ cells were analyzed for each sample.

Lymphocytes analyzed for $\mathrm{CD} 3 \zeta$ expression were first stained for appropriate surface antigens. Thereafter, cells were fixed and permeabilized using a Cytofix/Cytoperm Kit (Becton Dickinson) and incubated with PE-conjugated mAb's against $\mathrm{CD} 3 \zeta$

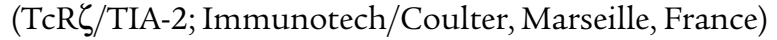
according to the protocol provided by the manufacturer. Finally, the cells were analyzed for $\mathrm{CD} 3 \zeta$ expression by use of flow cytometry.

Assay of $N K$ cell cytotoxicity. NK cell-mediated cytotoxicity against K562, an NK cell-sensitive leukemic cell line, was assayed as described elsewhere (14). NK cell-enriched lymphocytes $(100,000$ cells/well) were incubated in quadruplicates in 96-well microplates (Nunc A/S, Roskilde, Denmark) in the presence or absence of autologous monocytes (10,000-100,000 cells/well). All compounds were added at the onset of incubation, with the exception of formylmethionylleucyl-phenylalanine (fMLF; $0.1 \mu \mathrm{M})$ or $\mathrm{Hp}(2-20)(50$ $\mu \mathrm{M})$, which were added 20 minutes later. Finally, 10,000 ${ }^{51} \mathrm{Cr}$-loaded (Amersham, Stockholm, Sweden) K562 cells were added to the cell suspension. After incubation at $37^{\circ} \mathrm{C}$ for 16 hours, supernatant fluids 


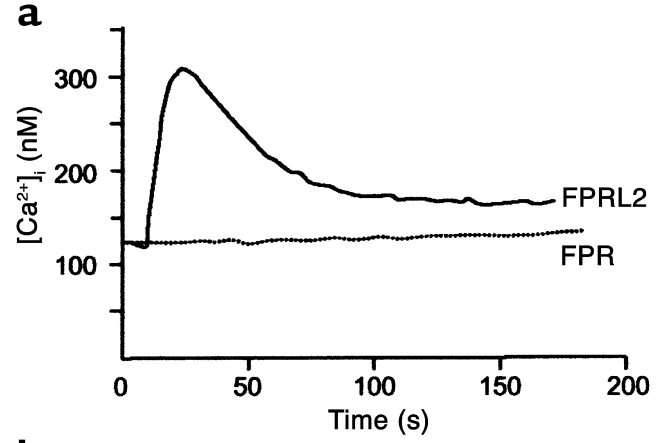

b

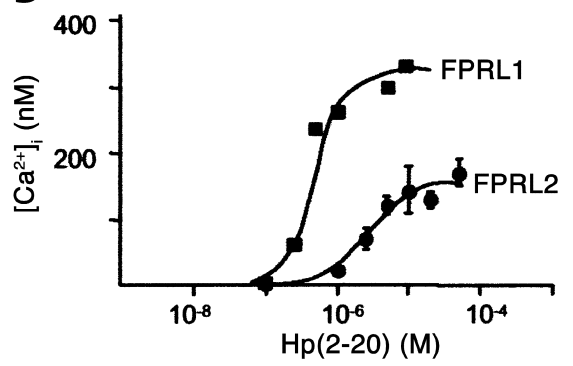

were collected by a tissue collecting system (Amersham) and assayed for radioactivity in a gamma-counter. NK cell cytotoxicity was calculated using the formula:

\section{Equation 1}

$100 \times \frac{\text { experimental }{ }^{51} \mathrm{Cr} \text { release }- \text { spontaneous release }}{\text { maximum release }- \text { spontaneous release }}=$ cell lysis $\%$

Cytosolic $\left[\mathrm{Ca}^{2+}\right]$ in HL-60 cells expressing FPRL1, FPRL2, and FPR. Stable expression of FPR, FPRL1, and FPRL2 in undifferentiated HL-60 cells was obtained as described, and their interaction with $\mathrm{Hp}(2-20)$ was determined by the ability of the peptide to mobilize intracellular $\left[\mathrm{Ca}^{2+}\right]$ in fura 2-loaded cells (16).

\section{Results}

A cecropin-like $H$. pylori peptide activates human monocytes

Chemotaxis and NADPH-oxidase activity. The $\mathrm{Hp}(2-20)$ peptide was found to be dose-dependently chemotactic for monocytes (Figure 1a). The maximal transmigration observed was only slightly lower than that induced by the well-characterized and efficacious monocyte chemoattractant fMLF. Monocyte chemoattractants commonly activate a specialized electron-transporting system, the NADPH-oxidase,

\section{Figure 3}

Desensitization of the $\mathrm{Hp}(2-20)(50 \mu \mathrm{M})$ response. Monocytes first activated with the agonist WKYMVm $(0.1 \mu \mathrm{M})$ (which desensitizes FPR, FPRL1 and FPRL2) were unable to generate a second burst of superoxide when challenged 10 minutes later with $\mathrm{Hp}(2-20)(\mathbf{a})$. Homologous desensitization with two subsequent stimulations of $\mathrm{Hp}(2-20)$ was also apparent (b). No desensitization against $\mathrm{Hp}(2-20)$-induced activation was obtained in monocytes first challenged with $\mathrm{fMLF}(0.1 \mu \mathrm{M})$ (which desensitizes only FPR) (c).

\section{Figure 2}

$\mathrm{Hp}(2-20)$-induced calcium mobilization in transfected HL-60 cells. Receptor interaction with $\mathrm{Hp}(2-20)(50 \mu \mathrm{M})$ was determined by measuring the ability of the peptide to mobilize intracellular calcium in undifferentiated HL-60 cells, stably transfected with either FPR, FPRL1, or FPRL2. Cells expressing the specific monocyte receptor FPRL2 responded with a rise in intracellular $\left[\mathrm{Ca}^{2+}\right]$, which peaked at approximately $300 \mathrm{nM}(\mathbf{a})$. The $\mathrm{EC}_{50}$ of the $\mathrm{Hp}(2-20)$-induced calcium mobilization in FPRL2-expressing cells was around $10 \mu \mathrm{M}$, whereas that for FPRL1 was approximately 30 -fold lower (b). No significant rise in intracellular $\left[\mathrm{Ca}^{2+}\right]$ occurred when $\mathrm{Hp}(2-20)$ was added to cells expressing FPR (a).

which ferries electrons to molecular oxygen. In this way, oxygen is reduced to superoxide anions, which in turn is converted to toxic oxygen products (17). The $\mathrm{Hp}(2-20)$ peptide induced a robust and dosedependent oxygen radical production (superoxide anion) in monocytes (Figure 1, b and c). The time course and magnitude of the response were comparable to those induced by fMLF (Figure 1b, inset). The Hp(2-20)-induced superoxide anion formation was inhibited by the NADPH-oxidase inhibitor DPI (18). A greater than $90 \%$ inhibition of $\mathrm{Hp}(2-20)$-induced activity was observed at a DPI concentration of $10 \mu \mathrm{M}$. In parallel experiments, DPI inhibited oxygen radical formation in response to fMLF, an established NADPH-oxidase activator (17) with similar efficacy and potency (not shown). These results suggest that $\mathrm{Hp}(2-20)$ is a true activator of the monocyte NADPH-oxidase.

An intact $\alpha$-helical structure of $H p(2-20)$ is required for monocyte activation. $\mathrm{Hp}(2-20)$ contains a

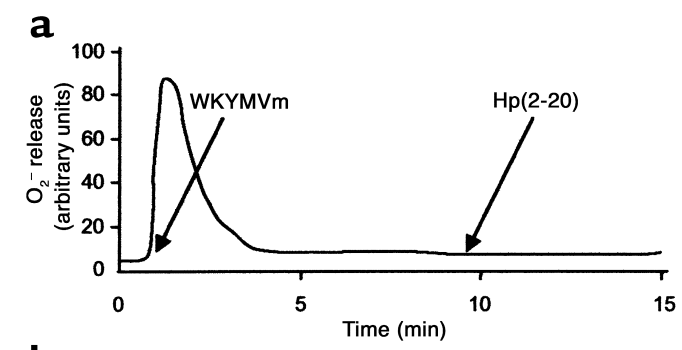

b
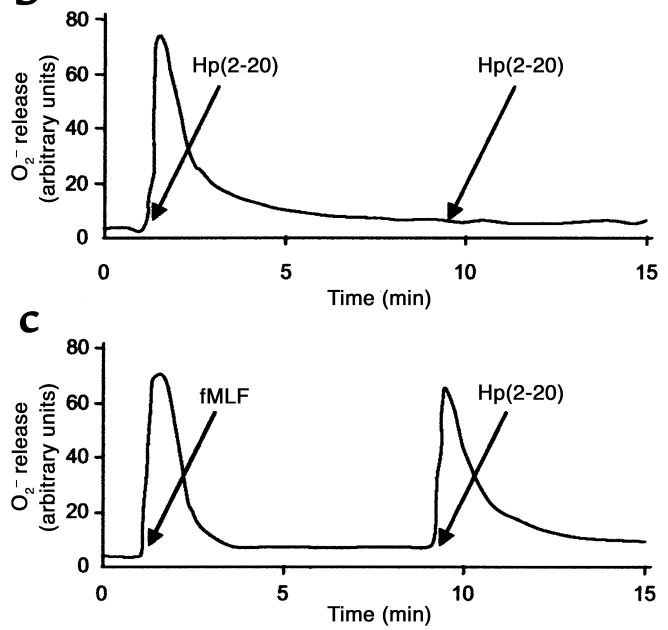


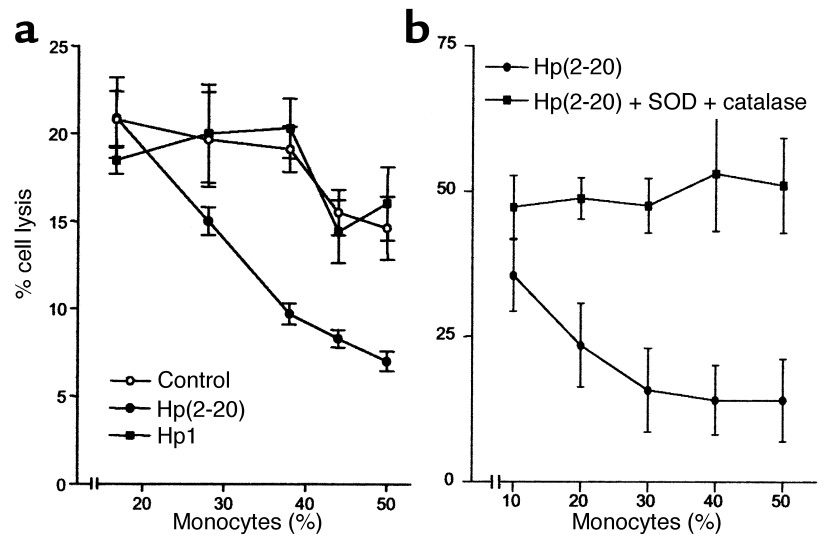

Figure 4

Monocyte-dependent inhibition of NK cell cytotoxicity by $\mathrm{Hp}(2-20)$ $(50 \mu \mathrm{M})$, reversal by oxygen radical scavengers. NK cell-enriched lymphocytes $\left(10^{5}\right.$ cells/well) were incubated with autologous monocytes for 16 hours at $37^{\circ} \mathrm{C}$ and assayed for cytotoxicity against ${ }^{51} \mathrm{Cr}$ labeled $\mathrm{K} 562$ cells $\left(10^{4}\right.$ cells/well). (a) The cell cultures were treated with culture medium (control, open circles), $\mathrm{Hp}(2-20)$ (filled circles), or the control peptide Hp1 $(50 \mu \mathrm{M})$ (filled boxes). Results are percentage of cell lysis (mean \pm SEM of quadruplicates). Hp (2-20) did not significantly affect cytotoxicity in the absence of monocytes (not shown) but enhanced the monocyte-induced inhibition of cytotoxicity at all monocyte/lymphocyte ratios investigated (a). The monocyte-dependent inhibition of NK cell cytotoxicity by $\mathrm{Hp}(2-20)$ was confirmed in ten experiments using blood from different donors. In these experiments, the $\mathrm{Hp}(2-20)$-induced inhibition was statistically significant over that induced by control monocytes at $37 \%$ monocytes $(P<0.005$; Wilcoxon's rank sum test) and $44 \%$ monocytes $(P<0.005)$. (b) The cell cultures were treated with $\mathrm{Hp}(2-20)$ (filled circles) or $\mathrm{Hp}(2-20)+\operatorname{SOD}(50 \mathrm{U} / \mathrm{ml})+$ catalase $(200 \mathrm{U} / \mathrm{ml})$ (filled boxes). Results are percentage of cell lysis (mean \pm SEM results from eight experiments using blood from different donors). At all monocyte/lymphocyte ratios above 1:5 monocytes, SOD + catalase significantly rescued $\mathrm{NK}$ cell cytotoxicity from $\mathrm{Hp}$ (2-20)-induced inhibition $(P<0.01-0.001$, Wilcoxon's rank sum test for pairs).

perfect amphipathic $\alpha$-helical structure, similar to those found in cecropins, which can be interrupted by replacing key amino acids $(16,19)$. Replacement of the lysine in position 9 of $\mathrm{Hp}(2-20)$ with leucine, an amino acid that lacks a polar side chain, interferes with the helical structure (19). No monocyte activation was obtained with the $\mathrm{K} \rightarrow \mathrm{L}$ substituted control peptide Hp1 (Figure 1b).

Hp(2-20) activates monocytes via FPRL1 and its monocyte-specific homologue FPRL2. By using undifferentiated HL-60 cells that had been stably transfected with FPR, FPRL1, or FPRL2, it was found that $\mathrm{Hp}(2-20)$ activated monocytes via FPRL1 and FPRL2, but not via FPR. Thus, cells expressing the specific monocyte receptor FPRL2 responded with a rise in intracellular $\left[\mathrm{Ca}^{2+}\right]$ reaching a level of approximately $300 \mathrm{nM}$ (Figure $2 \mathrm{a})$. The $\mathrm{EC}_{50}$ value of the $\mathrm{Hp}(2-20)$-induced calcium mobilization in FPRL2-expressing cells was approximately $10 \mu \mathrm{M}$, whereas that for FPRL1 was approximately 30 -fold lower (Figure $2 \mathrm{~b}$ ).

The supposition that $\mathrm{Hp}(2-20)$ activated monocytes via FPRL1 and FPRL2, but not via FPR, was confirmed in desensitization experiments using the agonists WKYMVm, which desensitizes FPR, FPRL1 and FPRL2, and AMLF, which desensitizes only FPR (20). Thus, monocytes first activated with WKYMVm were unable to generate a second burst of superoxide when subsequently challenged with $\mathrm{Hp}(2-20)$ (Figure 3a). A similar desensitization was observed after a reciprocal stimulation (not shown). Homologous desensitization with two subsequent stimulations of $\mathrm{Hp}(2-20)$ was also apparent (Figure $3 \mathrm{~b}$ ). No desensitization against $\mathrm{Hp}(2-20)$-induced activation occurred in monocytes first challenged with fMLF (Figure 3c).

\section{Lymphocyte inhibition and apoptosis} induced by $\mathrm{Hp}(2-20)$

Earlier studies reveal that monocytes/macrophages trigger functional inhibition of NK cells $(12,15)$. Our finding that $\mathrm{Hp}(2-20)$ potently triggered superoxide anion formation in monocytes prompted us to investigate effects of $\mathrm{Hp}(2-20)$ on monocyte-NK cell interactions. For this purpose, we incubated monocytes at various densities with autologous NK cell-enriched lymphocytes and monitored NK cell function and viability.

NK cell cytotoxicity. $\mathrm{Hp}(2-20)(50 \mu \mathrm{M})$, but not $\mathrm{Hp} 1$, effectively enhanced the monocyte-induced NK cell suppression (Figure 4a). The $\mathrm{Hp}(2-20)$-induced inhibition was significantly more pronounced than that induced by control monocytes and completely counteracted by treatment with a combination of the oxygen radical scavengers SOD and catalase (Figure 4b). More than $90 \%$ of the lymphocyte cytotoxicity was depleted by the removal of CD56 $6^{+} \mathrm{NK}$ cells by use of anti-CD56-coated beads (14); in contrast, removal of $\mathrm{CD}^{+} \mathrm{T}$ cells by use of anti-CD3-coated beads did not significantly reduce cytotoxicity (not shown).

Expression of $\mathrm{CD} 3 \zeta$. NK cells and other lymphocytes recovered from tumor-bearing animals (21) or patients with solid cancer disease, including gastric adenocarcinomas $(22,23)$, show a reduced expression of a critical signal-transducing molecule, $\mathrm{CD} 3 \zeta(\mathrm{TcR} \zeta)$. The proposed link between oxygen radical formation by monocyte/macrophages and cancer-related $\mathrm{CD} 3 \zeta$ disappearance (24), along with our finding that $\mathrm{Hp}(2-20)$ induced oxygen radical production, encouraged us to examine the $\mathrm{CD} 3 \zeta$ expression of NK cells after exposure to $\mathrm{Hp}(2-20)$-activated monocytes.

A problem in the study of $\mathrm{CD} 3 \zeta$ of NK cells is that the expression of characteristic surface markers on NK cells, such as CD56 or CD16, is strongly reduced by incubation with monocyte/macrophages. In contrast, $\mathrm{T}$ cells retain their main identification structure CD3E after exposure to monocytes $(12,15)$. Therefore, an appropriate method to detect changes in $\mathrm{CD} 3 \zeta$ expression is to study CD3ع- lymphocytes in NK cellfenriched lymphocyte preparations.

We found that $\mathrm{Hp}(2-20)$-activated monocytes, but not monocytes treated with $\mathrm{Hp} 1$ (not shown), induced the disappearance of $\mathrm{CD} 3 \zeta^{+}$cells from viable CD $3 \varepsilon^{-}$, NK cell-enriched lymphocytes; more than 

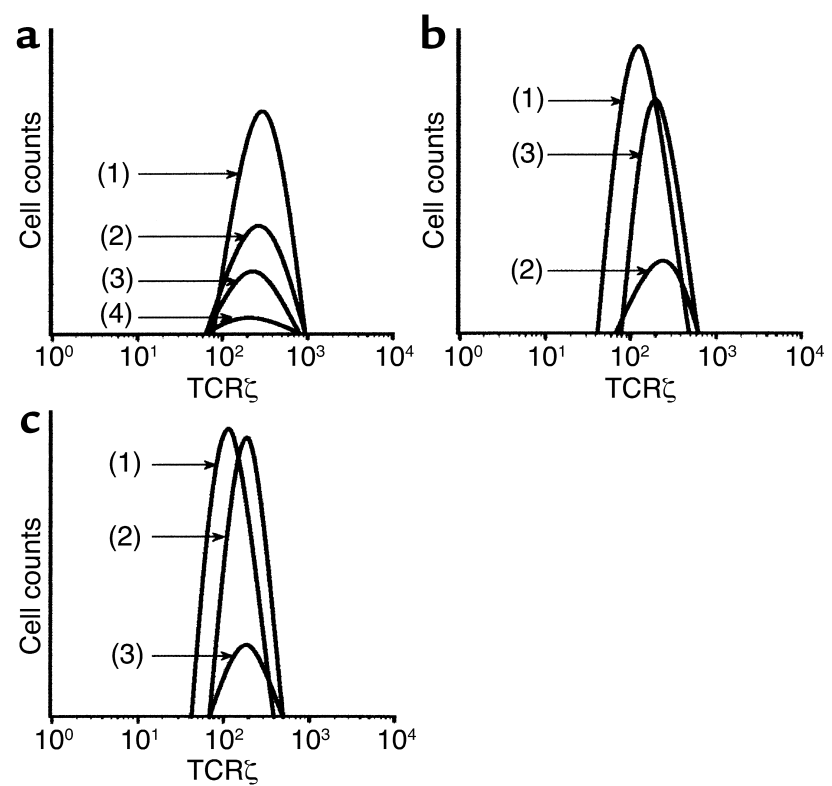

$80 \%$ of these lymphocytes were CD $56^{+} \mathrm{NK}$ cells (Figure $5 \mathrm{a}$ ). The inhibition was completely prevented by SOD and catalase (Figure $5 \mathrm{~b}$ ).

Apoptotic cell death in NK cells and T cells. An enhanced level of apoptosis is a common feature of lymphocytes recovered from patients with advanced gastric carcinoma (23). Morphological changes characteristic of lymphocyte apoptosis were observed after overnight incubation of lymphocytes with monocytes activated by $\mathrm{Hp}(2-20)$. The $\mathrm{Hp}(2-20)$-induced apoptosis was observed in NK cells and in CD3 $\varepsilon^{+} \mathrm{T}$ cells (Figure 6a). Apoptosis was confirmed by DNA fragmentation assay (TUNEL assay) and annexin V staining (refs. 14, 15 and not shown) and completely prevented by SOD and catalase (Figure 6b).

$T$ cell activation. We next determined the de novo expression of the early activation antigen CD69 (Leu23) on $\mathrm{CD} 3 \varepsilon^{+} \mathrm{T}$ cells obtained from a $\mathrm{T}$ cell-enriched lymphocyte fraction incubated in the presence or absence of $\mathrm{Hp}(2-20)$-activated monocytes. $\mathrm{CD} 3 \varepsilon^{+} \mathrm{T}$

\section{Figure 6}

$\mathrm{Hp}(2-20)$ triggers apoptosis in NK cells and T cells. Monocytes and/or NK cell-enriched lymphocytes were prepared as described in the legend to Figure 4. After incubation, cells in a lymphocyte gate were assayed for morphological features of apoptosis (reduced forward and increased right-angle scatter) by use of flow cytometry. (a) Data are the frequency of apoptotic CD56 $6^{+}$(NK; filled bars) or CD3 $\varepsilon^{+}$( $T$; open bars) after the following treatments: lymphocytes incubated in culture medium (control; lane 1 ) lymphocytes $+25 \%$ monocytes (lane 2 ), lymphocytes $+25 \%$ monocytes $+\mathrm{Hp}(2-20)(50 \mu \mathrm{M}$; lane 3$)$, lymphocytes $+50 \%$ monocytes (lane 4$)$, lymphocytes $+50 \%$ monocytes $+\mathrm{Hp}(2-20)$ (lane 5). The inset shows apoptosis induced by $\mathrm{Hp}(2-20)$-activated monocytes in all lymphocytes, and these data are the mean \pm SEM of three separate experiments. The results in $\mathbf{b}$ show the apoptosis of lymphocytes induced by $25 \%$ monocytes (light gray bars) or $50 \%$ monocytes (dark gray bars) activated with $\mathrm{Hp}(2-20)$ in cell mixtures treated with SOD + catalase (cat) or histamine (his) $(50 \mu \mathrm{M})$, alone or in the presence of the $\mathrm{H}_{2}$-receptor antagonist ranitidine $(\mathrm{ran})(50 \mu \mathrm{M})$.
Figure 5

$\mathrm{Hp}(2-20)(50 \mu \mathrm{M})$ triggers the disappearance of the signal-transducing molecule CD3 $\zeta$ from NK cells. Monocytes and/or NK cell-enriched lymphocytes were incubated as described in the legend to Figure 4. After incubation of the lymphocyte/monocyte mixture, cells in a CD3e- lymphocyte gate ( $>80 \%$ of which were CD56 ${ }^{+} \mathrm{NK}$ cells) were assayed for expression of $\mathrm{CD} 3 \zeta$ by use of flow cytometry. The histogram in a shows $\mathrm{CD} 3 \zeta$ expression by gated $\mathrm{CD} 3 \varepsilon^{-}$control lymphocytes $+25 \%$ monocytes (line 1), $\mathrm{Hp}(20-20)$-treated lymphocytes $+25 \%$ monocytes (line 2 ), control lymphocytes $+50 \%$ monocytes (line 3 ), and $\mathrm{Hp}(2-20)$-treated lymphocytes $+50 \%$ monocytes (line 4 ). The histogram in $\mathbf{b}$ shows corresponding $C D 3 \zeta$ expression of control $C D 3 \varepsilon^{-}$lymphocytes (line 1), $\mathrm{Hp}(20-20)$-treated lymphocytes $+25 \%$ monocytes (line 2$)$, and $\mathrm{Hp}(20$ 20 )-treated lymphocytes $+25 \%$ monocytes treated with catalase and SOD (line 3 ). The histogram in c shows CD3 $\zeta$ expression of control CD3 $\varepsilon^{-}$lymphocytes (line 1), $\mathrm{Hp}(20-20)$-treated lymphocytes $+25 \%$ monocytes + histamine ( $50 \mu \mathrm{M}$; line 2$)$, and $\mathrm{Hp}(20-20)$-treated lymphocytes $+25 \%$ monocytes + histamine + ranitidine $(50 \mu \mathrm{M}$; line 3$)$. The $\mathrm{Hp}(2-20)$ peptide was added 20 minutes after the onset of incubation. All data are expressed as percentage of $\mathrm{CD} 3 \zeta^{+}$cells in a $\mathrm{CD} 3 \varepsilon^{-}$gate, set to comprise only viable lymphocytes. Similar results were obtained in three separate experiments.

cells treated with IL-2 $(100 \mathrm{U} / \mathrm{ml})$ in the absence of monocytes acquired cell surface CD69. The IL-2-induced expression of CD69 was significantly reduced by monocytes, and the downregulation of CD69 was strongly potentiated by $\mathrm{Hp}(2-20)$ (Figure 7).
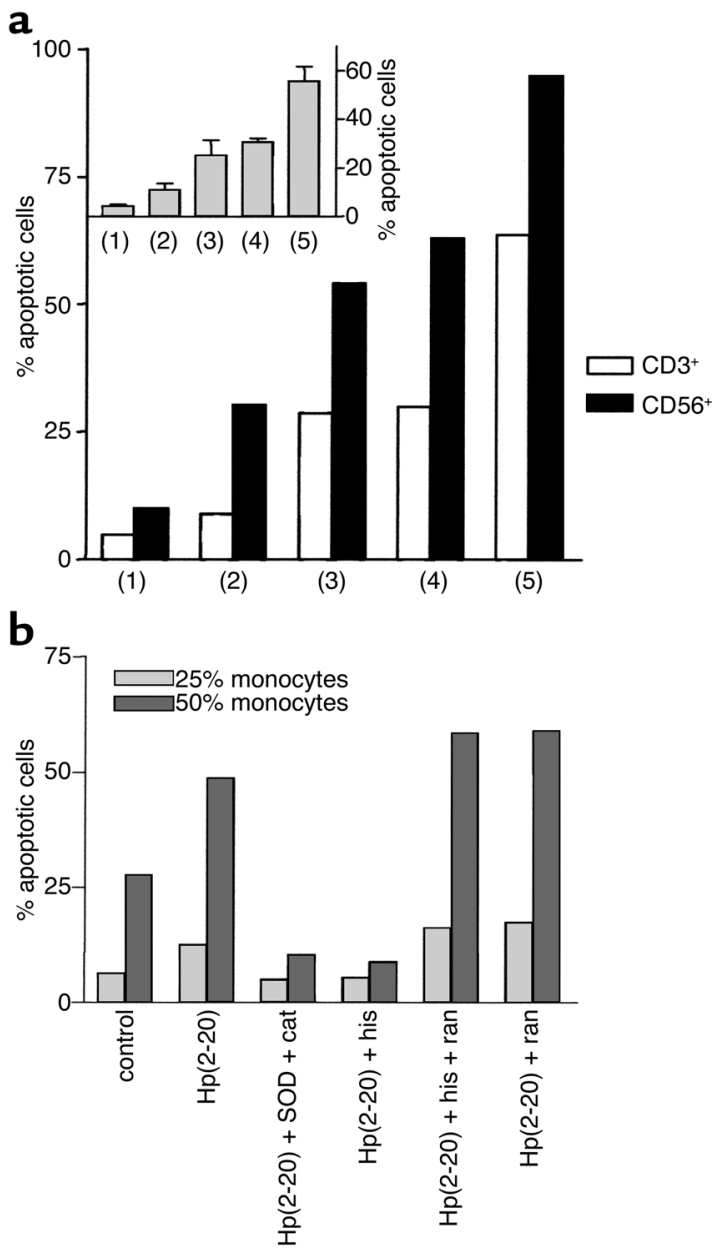


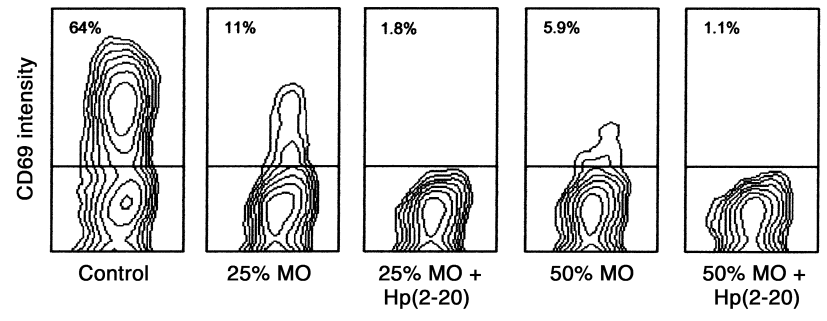

Figure 7

$\mathrm{Hp}(2-20)$ triggers functional inhibition of T cells. T cell-enriched lymphocytes were treated with culture medium (control) or admixed with $25 \%$ or $50 \%$ monocytes and $\mathrm{Hp}(2-20)(50 \mu \mathrm{M})$, as indicated. All cells were also treated with IL-2 $(100 \mathrm{U} / \mathrm{ml})$ during overnight incubation, followed by analysis of the activation marker CD69 in gated viable (nonapoptotic) CD3 $\varepsilon^{+}$lymphocytes by use of flow cytometry. $\mathrm{Hp}(2-20)$ did not alter the IL-2-induced acquisition of CD69 in T cells when incubated with lymphocytes without monocytes (not shown). Less than $3 \%$ of $C D 3 \varepsilon^{+} T$ cells expressed CD 69 before the addition of IL-2 or after incubation in culture medium overnight (not shown). Similar results were obtained in three separate experiments. $\mathrm{MO}$, monocytes.

More than $80 \%$ of NK cells acquired CD69 after treatment with IL-2 in the absence of monocytes. IL-2 weakly induced CD69 on NK cells when these cells were incubated with monocytes, and the inhibition was effectively potentiated by $\mathrm{Hp}(2-20)$ (not shown).

Histamine inhibits $\mathrm{Hp}(2-20)$-induced radical production and restores lymphocyte function and viability

Effect of histamine on NADPH-oxidase activity. The high concentrations of histamine normally present in the gastric mucosa (approximately 10-100 $\mu \mathrm{M}$; refs. 25, 26) led us to investigate the effects of histamine on $\mathrm{Hp}(2-20)$-induced oxygen radical formation in monocytes. Histamine markedly inhibited the oxygen radical formation induced by $\mathrm{Hp}(2-20)$, and the specific histamine $\mathrm{H}_{2}$-receptor antagonist ranitidine reversed the inhibition (Figure 8a).

Effect of histamine on NK cell and T cell function. Earlier studies show that histamine maintains NK cell and $\mathrm{T}$ cell function in the presence of suppressive phagocytes by inhibiting oxygen radical production (14, 15). We therefore investigated whether histamine protected NK cells and T cells from monocyteinduced, $\mathrm{Hp}(2-20)$-mediated suppression. Histamine prevented the following $\mathrm{Hp}(2-20)$-induced events: downregulation of $\mathrm{CD} 3 \zeta$ expression in NK cells/ $\mathrm{T}$ cells (Figure 5c), triggering of NK cell and $\mathrm{T}$ cell apoptosis (Figure 6b), and inhibition of NK cell antitumor activity (Figure 8b). The histamine-induced protection of T cells and NK cells was antagonized by ranitidine (Figure 5c, Figure 6b, and Figure 8b).

\section{Discussion}

In this study, we show that a $H$. pylori-derived peptide, $\mathrm{Hp}(2-20)$, is a monocyte chemoattractant that also triggers NADPH-oxidase-dependent oxygen radical forma- tion. In this regard, $\mathrm{Hp}(2-20)$ was as potent as previously identified $H$. pylori-derived proinflammatory peptides such as NAP and the peptide derived from the N-terminal portion of the bacterial urease (7-9). Monocyte activation was mediated by the FPRL1 as well as by an earlier orphan monocyte receptor, FPRL2. Several phagocyte chemoattractant receptors have been identified and characterized with respect to agonist binding, generation of intracellular signals, and cellular responses. FPRL1 (11, 27), which is the receptor shown earlier to recognize $\mathrm{Hp}(2-20)$ in neutrophils (11), binds to a broad spectrum of ligands that do not show any sequence homologies. FPRL1 binds $\mathrm{LXA}_{4}$ with high affinity and has been referred to as the $\mathrm{LXA}_{4}$ receptor (28). Other peptides/proteins with agonist activity at FPRL1 include a leucine zipperlike domain of the HIV-1 envelope gp41 (29), a peptide derived from the HIV-1 envelope gp120 (30), the acute-phase protein serum amyloid A (31), the mitochondrial peptide MYFINILTTL (32), LL-37, a bactericidal peptide derived from neutrophil cathelicidin (33), and the neurotoxic prion peptide fragment $\operatorname{PrP}_{106-126}$ (34). FPRL1 is thus a truly promiscuous receptor.

A third member of the FPR receptor family, FPRL2, which shows $83 \%$ amino acid sequence homology (particularly in the signaling cytoplasmic domain) with FPRL1 $(35,36)$, is expressed only by monocytes. No natural FPRL2 agonists have been identified. Our data demonstrate that $\mathrm{Hp}(2-20)$ activated monocytes also via FPRL2. It is, however, not possible to determine the relative contribution by FPRL1 and FPRL2 for the signals transduced until receptor-specific agonists/
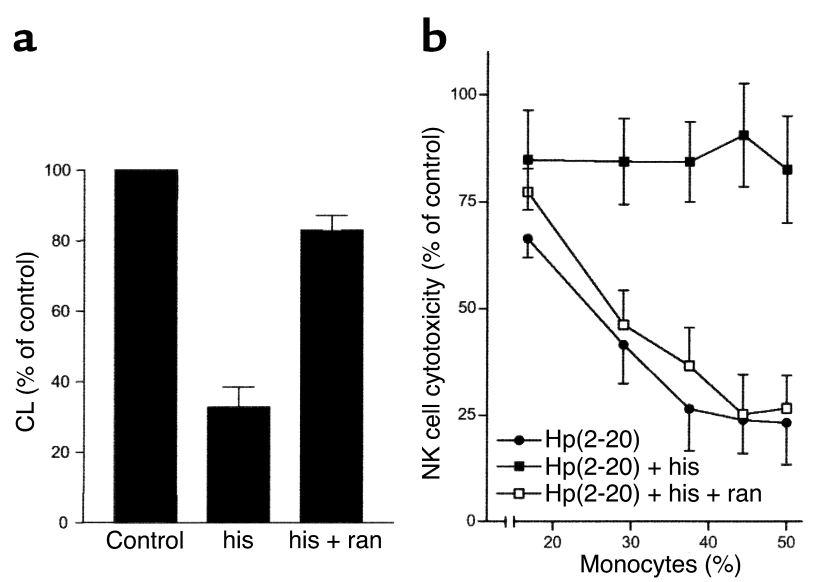

\section{Figure 8}

$\mathrm{Hp}(2-20)$-induced oxygen radical production and its inhibition by histamine. Superoxide anion production in elutriated monocytes was investigated by isoluminol-amplified CL (a). Cells were treated with histamine $(50 \mu \mathrm{M})$ or the histamine $\mathrm{H}_{2}$-receptor antagonist ranitidine $(50 \mu \mathrm{M})$. Data show mean values \pm SEM of four separate experiments. (b) Data are NK cell cytotoxicity against K562 target cells. The cells were prepared as described in the legend to Figure 5 and treated with $\mathrm{Hp}(2-20)(50 \mu \mathrm{M}$; filled circles), $\mathrm{Hp}(2-20)+$ histamine $(50 \mu \mathrm{M}$; filled boxes), or $\mathrm{Hp}(2-20)+$ histamine + ranitidine $(50 \mu \mathrm{M}$; filled boxes). Results are expressed as percentage of control, where $100 \%$ is the cell lysis percentage of control lymphocytes without monocytes added, and are the mean \pm SEM of four separate experiments. 
inhibitors become available. The finding that the synthetic peptide WKYMVm desensitized monocytes to a subsequent activation with $\mathrm{Hp}(2-20)$ strongly suggests that these agonists operate through the same receptor, but WKYMVm, in addition to being a high-affinity ligand for FPRL1, is an agonist also for FPRL2 (20). The results in this article identify $\mathrm{Hp}(2-20)$ as a new FPRL2 ligand, and the availability of novel agonists recognized by FPRL 2 will undoubtedly be of help in screening for other agonists and determine whether FPRL2 shows the same type of promiscuity as that described for FPRL1, as well as in identifying endogenous natural ligands for this receptor.

In a second part of this study, we report that monocytes activated by $\mathrm{Hp}(2-20)$ induce inhibition of NK cell and $\mathrm{T}$ cell function. Thus, the addition of $\mathrm{Hp}(2-20)$ to lymphocytes and monocytes in a mixture aimed at mimicking the mononuclear cell infiltrate of $H$. pylori-infected gastric tissue $(3,4)$ triggered inhibition of NK cell-mediated antitumor cytotoxicity, inhibition of $\mathrm{T}$ cell inducibility by IL-2, downregulation of the $\mathrm{CD} 3 \zeta$ transduction molecule expression by NK cells, and subsequent NK cell and $\mathrm{T}$ cell death by apoptosis. These inhibitory events were prevented by scavengers of NADPH-oxidase-derived oxygen radicals and were thus by all probability explained by the FPRL1/FPRL2-mediated oxygen radical induction by $\mathrm{Hp}(2-20)$.

An hypothesis emerging from these data is that the $\mathrm{Hp}(2-20)$ peptide may contribute to the recruitment and activation of monocyte/macrophages to the inflammatory tissue of $H$. pylori-infected gastric tissue. In this regard, $\mathrm{Hp}(2-20)$ was found to possess properties similar to those earlier described for other $H$. pylori-derived peptides such as a $61-\mathrm{kDa} \mathrm{N}$-terminal portion of the bacterial urease (7) and Hp-NAP (8). Our data may also have implications for the carcinogenesis in chronically infected gastritis tissue. Two properties of $\mathrm{Hp}(2-20)$ may be relevant for carcinogenesis: (a) triggering of the production of monocyte-derived oxygen radicals, which are mutagenic and potentially carcinogenic (17), and (b) a secondary suppression of lymphocytes relevant to the elimination of malignant cells.

It has been suggested that monocyte/macrophages may be responsible for the dysfunction of lymphocytes, including NK cells and T cells, which is frequently observed at the site of neoplastic tumor growth (24, 37). Much attention has been focused on the defective expression of $\mathrm{CD} 3 \zeta$, a transduction molecule expressed by NK cells and $\mathrm{T}$ cells, in lymphocytes from cancer patients, including those with gastric adenocarcinoma $(22,23)$. The disappearance of $\mathrm{CD} 3 \zeta$ has been attributed to oxygen radical production by monocyte/macrophages $(21,38)$. Our finding that $\mathrm{Hp}(2-20)$, by triggering oxygen radical formation in monocytes, induced the disappearance of $\mathrm{CD} 3 \zeta$ from lymphocytes suggests that this peptide may contribute to lymphocyte dysfunction in gastric adenocarcinoma. It is noteworthy that changes typical for lymphocytes recovered from patients with invasive gastric carcino- mas, such as $\mathrm{CD} 3 \zeta$ downmodulation and apoptosis $(23,39)$, were induced by the $\operatorname{Hp}(2-20)$ peptide in vitro. However, it should be emphasized that further studies are needed to clarify the putative role of $\mathrm{Hp}(2-20)$ in gastric carcinogenesis.

Finally, a gastric mucosal constituent, histamine, was found to reduce or inhibit the $\mathrm{Hp}(2-20)$-induced formation of oxygen radicals and thereby protect $\mathrm{T}$ cells and NK cells from functional inhibition and apoptotic cell death. This effect of histamine was clearly mediated by histamine $\mathrm{H}_{2}$ receptors expressed by monocytes, and concentrations of histamine similar to those detected in human gastric mucosal tissue (25, 26) were sufficient to mediate the protective effects. A tentative hypothesis emerging from these data is that the monocyte recruitment and activation induced by $\mathrm{Hp}(2-20)$, and presumably also by other $H$. pylori-derived proinflammatory peptides, may be balanced by the availability of histamine at monocyte histamine $\mathrm{H}_{2}$ receptors. Given that monocyte activation is a prominent feature of $H$. pylori-induced gastritis, this hypothesis is supported by the findings that ranitidine treatment, in addition to relieving acid-related symptoms, reportedly also markedly aggravates antral and corporal gastric inflammation (40). Further studies including, for example, the function and viability of gastric mucosal NK cells and T cells in $H$. pylori-infected subjects are required to determine the in vivo relevance of these novel mechanisms.

\section{Acknowledgments}

This study was supported by the Swedish Cancer Foundation (Cancerfonden), the Swedish Medical Research Council, and Maxim Pharmaceuticals Inc. K. Hellstrand is a fellow of the Swedish Cancer Society.

1. Graham, D.Y. 2000. Helicobacter pylori infection is the primary cause of gastric cancer. J. Gastroenterol. 35:90-97.

2. Ebert, M.P., Yu, J., Sung, J.J., and Malfertheiner, P. 2000. Molecular alterations in gastric cancer: the role of Helicobacter pylori. Eur. J. Gastroenterol. Hepatol. 12:795-798.

3. Agnihotri, N., et al. 1998. Characterization of lymphocytic subsets and cytokine production in gastric biopsy samples from Helicobacter pylori patients. Scand. J. Gastroenterol. 33:704-709.

4. Li, H., Andersson, E.M., and Helander, H.F. 1999. Reactions from rat gastric mucosa during one year of Helicobacter pylori infection. Dig. Dis. Sci. 44:116-124.

5. Takeuchi, H., et al. 2001. Prognostic significance of natural killer cell activity in patients with gastric carcinoma: a multivariate analysis. Am. J. Gastroenterol. 96:574-578.

6. Ishigami, S., et al. 2000. Prognostic value of intratumoral natural killer cells in gastric carcinoma. Cancer. 88:577-583.

7. Mai, U.E., et al. 1992. Surface proteins from Helicobacter pylori exhibit chemotactic activity for human leukocytes and are present in gastric mucosa. J. Exp. Med. 175:517-525.

8. Satin, B., et al. 2000. The neutrophil-activating protein (HP-NAP) of Helicobacter pylori is a protective antigen and a major virulence factor. J. Exp. Med. 191:1467-1476.

9. Allen, L.A. 2000. Modulating phagocyte activation: the pros and cons of Helicobacter pylori virulence factors. J. Exp. Med. 191:1451-1454.

10. Putsep, K., Branden, C.I., Boman, H.G., and Normark, S. 1999. Antibacterial peptide from $H$. pylori. Nature. 398:671-672.

11. Bylund, J., et al. 2001. Proinflammatory activity of a cecropin-like antibacterial peptide from Helicobacter pylori. Antimicrob. Agents Chemother. 45:1700-1704.

12. Hansson, M., Asea, A., Ersson, U., Hermodsson, S., and Hellstrand, K. 1996. Induction of apoptosis in NK cells by monocyte-derived reactive oxygen metabolites. J. Immunol. 156:42-47. 
13. Dahlgren, C., and Karlsson, A. 1999. Respiratory burst in human neutrophils. J. Immunol. Methods. 232:3-14.

14. Mellqvist, U.H., et al. 2000. Natural killer cell dysfunction and apoptosis induced by chronic myelogenous leukemia cells: role of reactive oxygen species and regulation by histamine. Blood. 96:1961-1968.

15. Hansson, M., et al. 1999. Histamine protects T cells and natural killer cells against oxidative stress. J. Interferon Cytokine Res. 19:1135-1144.

16. Boman, H.G. 2000. Innate immunity and the normal microflora. Immunol. Rev. 173:5-16.

17. Klebanoff, S.J. 1999. Oxygen metabolites from phagocytes. In Inflammation: basic principles and clinical correlates. Volume 1. 3rd edition. J.I. Gallin and R. Snyderman, editors. Lippincott Williams \& Wilkins. Philadelphia, Pennsylvania, USA. 721-768.

18. O’Donnell, B.V., Tew, D.G., Jones, O.T., and England, P.J. 1993. Studies on the inhibitory mechanism of iodonium compounds with special reference to neutrophil NADPH oxidase. Biochem. J. 290:41-49.

19. Putsep, K., Normark, S., and Boman, H.G. 1999. The origin of cecropins; implications from synthetic peptides derived from ribosomal protein L1. FEBS Lett. 451:249-252.

20. Christophe, T., et al. 2001. The synthetic peptide Trp-Lys-Tyr-Met-ValMet-NH2 specifically activates neutrophils through FPRL1/LXA4R and is an agonist for the orphan monocyte-expressed chemoattractant receptor FPRL2. J. Biol. Chem. 276:21585-21593.

21. Aoe, T., Okamoto, Y., and Saito, T. 1995. Activated macrophages induce structural abnormalities of the T cell receptor-CD3 complex. J. Exp. Med. 181:1881-1886.

22. Kono, K., Ichihara, F., Iizuka, H., Sekikawa, T., and Matsumoto, Y. 1998. Expression of signal transducing T-cell receptor zeta molecules after adoptive immunotherapy in patients with gastric and colon cancer. Int. J. Cancer. 78:301-305.

23. Takahashi, A., et al. 2001. Elevated caspase-3 activity in peripheral blood $\mathrm{T}$ cells coexists with increased degree of T-cell apoptosis and down-regulation of TCR zeta molecules in patients with gastric cancer. Clin. Cancer Res. 7:74-80.

24. Kiessling, R., et al. 1999. Tumor-induced immune dysfunction. Cancer Immunol. Immunother. 48:353-362.

25. Bechi, P., et al. 1993. Reflux-related gastric mucosal injury is associated with increased mucosal histamine content in humans. Gastroenterology. 104:1057-1063.

26. Lonroth, H., Rosengren, E., Olbe, L., and Lundell, L. 1990. Histamine metabolism in human gastric mucosa. Effect of pentagastrin stimulation. Gastroenterology. 98:921-928

27. Bao, L., Gerard, N.P., Eddy, R.L., Jr., Shows, T.B., and Gerard, C. 1992. Mapping of genes for the human C5a receptor (C5AR), human FMLP receptor (FPR), and two FMLP receptor homologue orphan receptors (FPRH1, FPRH2) to chromosome 19. Genomics. 13:437-440.

28. Fiore, S., Maddox, J.F., Perez, H.D., and Serhan, C.N. 1994. Identification of a human cDNA encoding a functional high affinity lipoxin A4 receptor. J. Exp. Med. 180:253-260.

29. Su, S.B., et al. 1999. T21/DP107, A synthetic leucine zipper-like domain of the HIV-1 envelope gp 41, attracts and activates human phagocytes by using G-protein- coupled formyl peptide receptors. J. Immunol. 162:5924-5930.

30. Deng, X., et al. 1999. A synthetic peptide derived from human immunodeficiency virus type $1 \mathrm{gp} 120$ downregulates the expression and function of chemokine receptors CCR5 and CXCR4 in monocytes by activating the 7-transmembrane G-protein- coupled receptor FPRL1/LXA4R. Blood. 94:1165-1173.

31. Su, S.B., et al. 1999. A seven-transmembrane, G protein-coupled receptor, FPRL1, mediates the chemotactic activity of serum amyloid A for human phagocytic cells. J. Exp. Med. 189:395-402.

32. Chiang, N., Fierro, I.M., Gronert, K., and Serhan, C.N. 2000. Activation of lipoxin $\mathrm{A}(4)$ receptors by aspirin-triggered lipoxins and select peptides evokes ligand-specific responses in inflammation. J. Exp. Med. 191:1197-1208.

33. De, Y., et al. 2000. LL-37, the neutrophil granule- and epithelial cellderived cathelicidin, utilizes formyl peptide receptor-like 1 (FPRL1) as a receptor to chemoattract human peripheral blood neutrophils, monocytes, and T cells. J. Exp. Med. 192:1069-1074.

34. Le, Y., et al. 2001. The neurotoxic prion peptide fragment $\operatorname{PrP}(106-126)$ is a chemotactic agonist for the $G$ protein-coupled receptor formyl peptide receptor-like 1. J. Immunol. 166:1448-1451.

35. Durstin, M., Gao, J.L., Tiffany, H.L., McDermott, D., and Murphy, P.M. 1994. Differential expression of members of the $\mathrm{N}$-formylpeptide receptor gene cluster in human phagocytes. Biochem. Biophys. Res. Commun 201:174-179.

36. Ye, R.D., and Boulay, F. 1997. Structure and function of leukocyte chemoattractant receptors. Adv. Pharmacol. 39:221-289.

37. Elgert, K.D., Alleva, D.G., and Mullins, D.W. 1998. Tumor-induced immune dysfunction: the macrophage connection. J. Leukoc. Biol. 64:275-290.

38. Nakagomi, H., et al. 1993. Decreased expression of the signal-transducing zeta chains in tumor-infiltrating T-cells and NK cells of patients with colorectal carcinoma. Cancer Res. 53:5610-5612.

39. Kim, C.W., et al. 1999. Alteration of signal-transducing molecules and phenotypical characteristics in peripheral blood lymphocytes from gastric carcinoma patients. Pathobiology. 67:123-128.

40. Meining, A., Bosseckert, H., Caspary, W.F., Nauert, C., and Stolte, M 1997. H2-receptor antagonists and antacids have an aggravating effect on Helicobacter pylori gastritis in duodenal ulcer patients. Aliment. Phar macol. Ther. 11:729-734. 